\title{
NARRATIVAS E FOTOGRAFIAS: MEMÓRIAS DO TEMPO VIVIDO NA RUÍNA “CASA E BAZAR NAZARÉ DE IZIDORO CUNHA JÚNIOR”, EM SANTANA DO CAPIM-PA
}

\author{
Adão Souza Borges ${ }^{1}$ \\ Maria das Graças Ferraz ${ }^{2}$
}

\section{Introdução}

Foi tentando olhar o tempo vivido por meio de artefatos do passado, de fotografias e das memórias de pessoas que viveram/vivem numa ruína às margens do rio Capim é que remamos em busca da compreensão de como o presente lida com o passado, e assim ancoramos nossa canoa no porto da memória, este fenômeno capaz de buscar as tramas sociais cotidianas e reviver cenários do tempo e do espaço, que só é possível através das reminiscências dos sujeitos.

Partimos da indagação de como a ruína Casa e Bazar Nazaré de Izidoro Cunha Júnior é vivenciada nos dias atuais, quando a energia elétrica é uma realidade nas residências, quando a vida tem a direção não somente do rio e igarapés como antes, mas também da malha asfáltica da PA 252, que liga a vila de Santana do Capim à sede do município de Aurora do Pará e demais cidades do nordeste paraense, e, quando aquele empreendimento resume-se às paredes em ameaças de queda, ao balcão sem vendedores e compradores, às prateleiras vazias e à balança sem pratos e nem pesos para medir. $\mathrm{O}$ que resta do passado além das prateleiras, balcão, balança, cofre, artesanato e oratório familiar? Resta o passado nas memórias das pessoas mais antigas da vila de Santana e nas memórias dos familiares do falecido proprietário, que até hoje preservam artefatos, que simbolizam o apogeu daquele comércio, e objetos pessoais da família.

Utilizamos, neste estudo, o entendimento de que a fotografia não pode ser vista apenas como um recurso capaz de congelar o tempo pretérito, mas como uma fonte rica para refletir acerca de práticas sociais desenvolvidas pelos sujeitos que tecem ou teceram relações cotidianas no espaço e num tempo que pode ser revelado através de narrativas. Dessa forma, acreditamos numa interlocução entre a linguagem escrita e a visual capaz de produzir narrativas que não se anulam, mas que dialogam entre si para discutir as trajetórias do tempo vivido das pessoas que protagonizaram, durante aquele

\footnotetext{
${ }^{1}$ Universidade Federal do Pará, Brasil.

${ }^{2}$ Universidade Federal do Pará, Brasil.
} 
estabelecimento comercial, uma história de riquezas na família, bem como as representações do passado a partir dos objetos que ainda restam do tempo de glamour e do poder que a família ostentava na vila de Santana do Capim e região ribeirinha.

Neste trabalho, recorremos à história oral como suporte metodológico capaz de registrar as vozes dos sujeitos da comunidade indicados como "guardiões da memória" da Casa e Bazar Nazaré de Izidoro Cunha Júnior: Vera Lúcia Cunha e Reginaldo Cunha (herdeiros), dona Ana Pantoja e dona Bahia, que autorizaram a publicação de suas fotografias e de suas narrativas.

\section{A Casa Bazar Nazaré na memória do povo de Santana do Capim}

A discussão que gira em torno da memória nos faz lembrar o seu papel de destaque na vida de diferentes povos. Na Grécia antiga, a memória era compreendida como algo sobrenatural cuja atribuição cabia à deusa Mnemosine. Para o povo grego, o registrar algo tornava-se um fator que contribuía para o enfraquecimento da memória. Movidos por essa preocupação, os gregos desenvolveram técnicas para preservar a lembrança sem recorrer à escrita, o que conferia aos poetas um papel relevante.

Os gregos da época fizeram da Memória uma deusa, Mnemosine. É a mãe das nove musas que ela propiciou no decurso de nove noites passadas com Zeus. Lembra aos homens a recordação dos heróis e dos seus altos feitos, preside a poesia lírica. $\mathrm{O}$ poeta é, pois um homem possuído pela memória, o aedo é um adivinho do passado, como o adivinho o é do futuro. É a testemunha inspirada dos "tempos antigos", da idade das origens. (Le Goff, 1990: 451).

O povo romano tratou a memória como fator indispensável para a arte da retórica, que objetivava a emocionar o público por meio da linguagem. No período medieval, com o cristianismo, é dada a memória litúrgica que pauta o presente da rememoração dos acontecimentos.

O advento da imprensa implicou uma vasta influência sobre a memória tanto individual como coletiva. De uma sociedade tradicionalmente oral passa-se para uma sociedade do registro escrito até se chegar à era da memória eletrônica do computador, capaz de armazenar imensas quantidades de informações. 
Quando se fala em memória, a primeira idéia que surge é de que ela é a propriedade particular de guardar informações, o que nos remete a um conjunto de funções psíquicas dos campos da Psicologia, Psicofisiologia e Neurofisiologia. Pensase, dessa forma, a memória como algo eminentemente orgânico, que, para Durkheim (1970: 28), “a memória não é um fenômeno puramente físico, cujas representações são suscetíveis de se conservar".

Para os estudiosos do assunto, a memória é o resultado do entrelaçamento das experiências de um tempo vivido. Ela é uma espécie de "guardiã" do tempo vivido de cada indivíduo, que assegura a existência de acontecimentos que marcaram uma época e garante partilha desses acontecimentos entre indivíduos de um grupo, que no nosso caso é a experiência vivida com os familiares e vizinhos da família do senhor Izidoro Cunha Júnior, na Casa Bazar Nazaré. Nessa esteira, Milton Santos (2008: 329) lembra que "a memória coletiva é apontada como um cimento indispensável à sobrevivência das sociedades, o elemento de coesão garantidor da permanência e da elaboração do futuro".

A memória enquanto lugar das lembranças não é um produto qualquer resultante apenas de vivências, mas um processo que se faz no presente para atender às suas necessidades. É por isso que se pode refletir que o passado não é guardado pela simples evocação das lembranças, mas reconstruído numa perspectiva do presente. Dessa forma, pode-se dizer que a memória está associada ao tempo da experiência, vivido na cultura. Quando se rememoram os acontecimentos no tempo, recostura-se, tece-se o passado no presente, envolvendo as tramas e entrelaçando novas experiências da existência.

Para a tessitura do passado, na ruína em estudo, é imprescindível associarmos a discussão da memória à da narrativa, pois entendemos que as duas se imbricam para o engendramento do tempo passado com o presente.

Walter Benjamim (1994: 30), ao discorrer sobre o narrador, tece diversas considerações que nos permitem pensar sobre a importância de uma das mais antigas formas de expressão popular: o ato de narrar. Para o autor, a narrativa é uma experiência acumulada ao longo das vivências, e tem como matéria-prima a oralidade. Para o filósofo alemão, narrar é intercambiar experiências, que são tecidas e alimentadas quotidianamente na memória.

Recentemente, a utilização de narrativas vem focando as motivações sobre as suas construções e não apenas as da estrutura da linguagem, mas insistindo em querer saber por que as narrativas estão tão presentes no nosso dia a dia, quando, inclusive, 
uma fotografia de uma ruína torna-se uma narrativa, pois é capaz de externalizar e internalizar experiências vividas pelas pessoas que as contam, originando versões ouvidas diferentes e reconstruídas, tornando-se reflexões que estão sempre em movimento.

Narrar é experienciar a vida, como se tece um fio de acontecimentos que envolvem personagens (no nosso caso, os herdeiros da Casa Bazar Nazaré, Vera Lúcia Cunha, Ronaldo Cunha, Ana Pantoja e dona Bahia) num lugar e num tempo determinado.

Para Tzvetan Todorov, uma narrativa:

Se constitui na tensão de duas forças. Uma é a mudança, o inexorável curso dos acontecimentos, a interminável narrativa da "vida" (a história), onde cada instante se apresenta pela primeira e última vez. É o caos que a segunda força tenta organizar; ela procura dar-lhe um sentido, introduzir uma ordem. Essa ordem se traduz pela repetição (ou pela semelhança) dos acontecimentos: o momento presente não é original, mas repete ou anuncia instantes passados e futuros. A narrativa nunca obedece a uma ou a outra força, mas se constitui na tensão das duas. (Todorov, 2006: 20-21)

O autor compreende a narrativa enquanto produto da história pelo fato de que, na narrativa, o momento presente não é um tempo passado, um tempo que fala dos fatos guardados na memória, a qual constrói saberes para a coletividade e possibilita no indivíduo criatividade e enriquecimento dos fatos e das tramas sociais.

Ecléa Bosi, ao estudar as memórias de velhos na sociedade paulistana, demonstra a importância destes para a construção da história e inaugura uma forma de pensar a velhice na sociedade industrial, a partir do tratamento dispensado aos velhos, sendo a experiência vivida um dos elementos negados no tempo da produção da mercadoria; e negar a experiência significa negar o outro que teceu trajetórias, experienciou, viveu! Dessa forma, a experiência do vivido é compreendida pela sociedade industrial como declínio, prenúncio do fim, morte da experiência acompanhada da castração física.

A velhice, que é um fator natural como a cor da pele, é tomada preconceituosamente pelo outro. Há, no transcorrer da vida, momentos de crise de identificação: na adolescência também nossa imagem se quebra, mas o adolescente está em um período de transição, não de declínio. O velho sente-se um indivíduo diminuído, que luta para continuar sendo um homem. O coeficiente de adversidade das coisas cresce: as escadas ficam mais duras de subir, as distâncias mais longas a percorrer, as ruas mais perigosas de atravessar, os pacotes ficam mais pesados de carregar. $\mathrm{O}$ 
mundo fica eriçado de ameaças, de ciladas. Uma falha, uma pequena distração, são severamente castigados. (Bosi, 2004: 79).

A autora enfatiza a existência de duas memórias, uma formada pelos hábitos e costumes que acontecem na memória social, e outra, da reminiscência, da revivescência do passado, e acha ser esta última a memória dos velhos pronta para aconselhar os mais jovens, porque eivada de experiências.

As narrativas que utilizamos neste trabalho são frutos das experiências de vida de sujeitos que vivenciaram um espaço e um tempo que já não existem mais no presente, mas no exercício da memória, ou seja, da rememoração. Foram as lembranças de dona Vera Lúcia Cunha, do senhor Reginaldo Cunha, de dona Ana Pantoja e dona Bahia que se voltaram ao passado e reconstituíram um tempo cuja escritura não existe lavrada em lugar algum, senão em suas memórias. Sobre este tempo só revive quem o experimentou, comprando ou vendendo, e, sobretudo, quem conheceu seu Izidoro Cunha, sua família, seus amigos e as tramas sociais tecidas num tempo e num espaço em que o rio direcionava a prática do comércio e o modo de vida das pessoas, até a "modernização" da vila, metaforizada pela construção de estradas, a chegada da energia elétrica e a rapidez dos motores dos barcos e das lanchas que encurtaram o tempo da viagem de Santana do Capim à capital Belém.

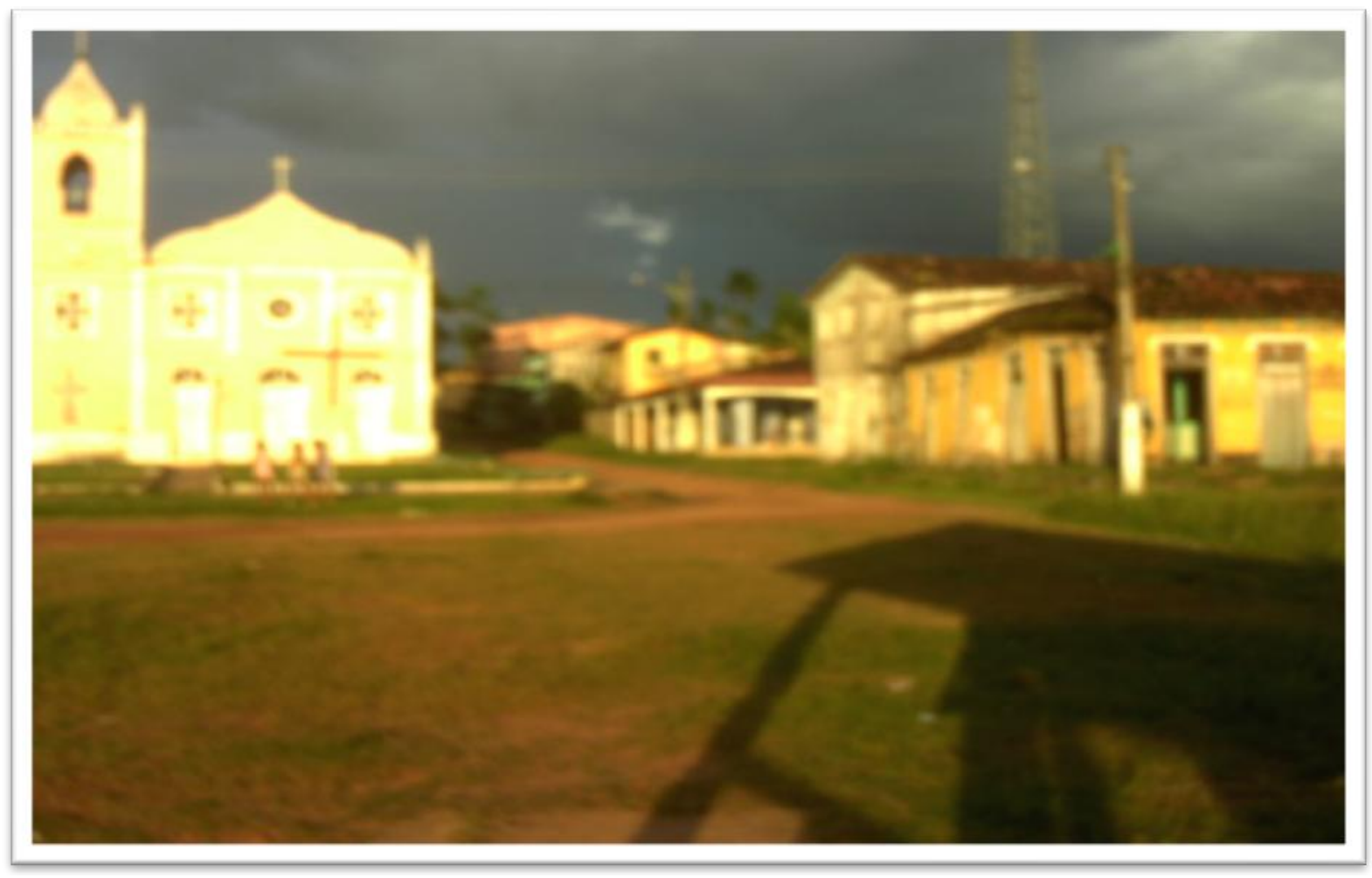

Foto 1 - Frente de Vila Santa do Capim. Autoria: Adão Souza Borges. 
Nos estudos de Marin e Castro (2004: 34) sobre as experiências de grupos negros do Pará, a Vila Santana do Capim aparece na demografia da região de Belém, em 1823, como uma freguesia da capital paraense, com um contingente populacional de 992 moradores livres e 663 escravos. Sua decadência, bem como as das demais que compunham esta estatística, é apontada pela grande influência dos processos sociais e políticos comandados a partir da cidade.

Revoltas camponesas, fuga de trabalhadores livres e de escravos e a organização de quilombos representaram rupturas com a ordem estabelecida pelas elites que, em geral, abandonavam seus negócios localizados nas áreas distantes, preferindo ter cargos públicos e benesses especiais a cuidar de suas fazendas e engenhos. (Marin; Castro, 2004: 35).

Assim, o espaço da feitoria aos poucos ficou abandonado, sendo que as terras pertencentes àquela feitoria foram doadas à Diocese da Igreja Católica de Bragança, onde encontramos vestígios daquela época por meio das ruínas dos engenhos de moagem de cana-de-açúcar, como é o caso da Aproaga e do engenho do Calixto, nas proximidades de Santana de Capim, hoje, reivindicados pelos descendentes de escravos enquanto territórios de identidades de descendentes de escravos.

As emancipações políticas que ocorreram no Estado do Pará na década de 90, das quais o município de Aurora do Pará fez parte, concederam-lhe a vila de Santana do Capim como parte de seu território político, tornando-se responsável pela manutenção das políticas públicas, como educação, saúde, agricultura, etc.

A vila de Santana do Capim está localizada às margens do rio Capim, dista da sede do município em 36 quilômetros, compõe grande parte do território ribeirinho do município e possui uma população de quatro mil habitantes, cuja maioria é de jovens na faixa etária de 15 a 24 anos de idade, seguida de crianças de 0 a 12 anos, conforme censo da Secretaria Municipal de Saúde/Aurora do Pará, 2011. Em termos de organização política, é considerada um polo central que atende as demais comunidades ribeirinhas vizinhas, com duas escolas que contemplam as redes municipal e estadual de ensino (inclusive com o ensino médio regular), com um Posto de Saúde da Família e com transportes de alunos que residem nas comunidades ribeirinhas e assentamentos adjacentes.

A base econômica dos habitantes de Santana do Capim é garantida pela produção de farinha de mandioca, o extrativismo da castanha do Pará, a coleta do açaí, o 
desdobramento de madeira, que acontece numa serraria, e uma cerâmica que fica às margens da vila, bem como pelo emprego no serviço público.

No que se refere aos prédios antigos, nenhuma iniciativa política foi procedida pelo Estado para preservar o engenho e sobrados do século XVIII, que garantiram a produção de aguardente e de açúcar por meio do trabalho escravo naquele lugar, sendo que o material de concreto das paredes destes prédios foi utilizado para a construção do muro de arrimo e do "cais" da vila. Nessa perspectiva, surgiu o interesse em refletir como o passado é tratado dentro de uma comunidade tradicional, como identificamos Santana do Capim a partir de uma ruína, a Casa Bazar Nazaré de Izidoro Cunha Júnior.

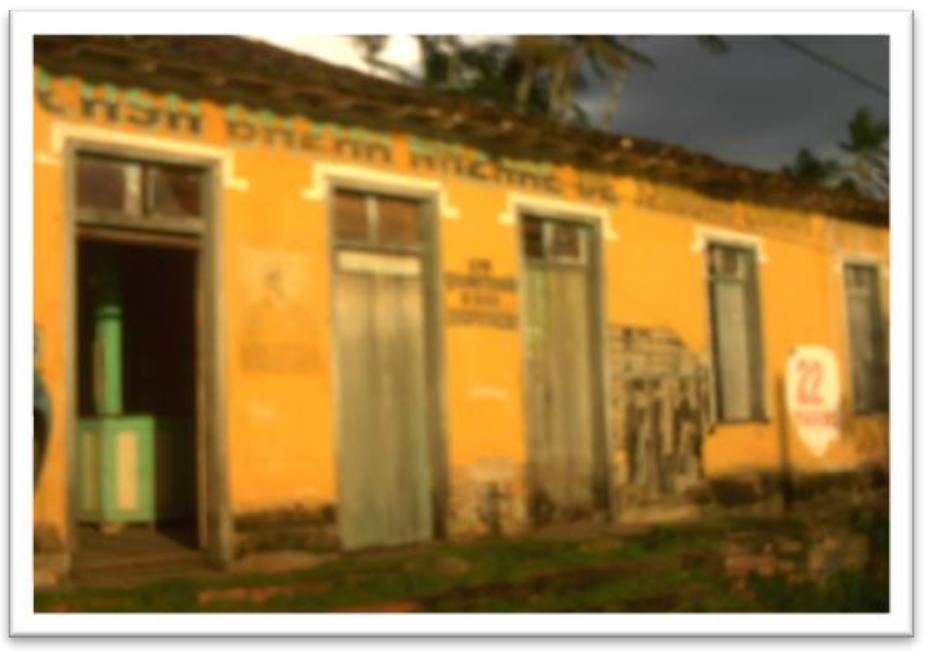

Foto 2 - Casa e bazar Nazaré de Izidoro Cunha Júnior. Foto de Adão Borges.

O que denominamos ruína, hoje, foi no final da década de 50 e início dos anos 60 um grande empreendimento comercial, de propriedade do senhor Izidoro Cunha Júnior. Localizada no centro da vila de Santana do Capim, às margens do rio Capim, essa casa foi um dos maiores centros comerciais da região ribeirinha, com gêneros alimentícios, bazar e armarinho, bebidas e farmácia. O atendimento aos fregueses era feito por seis vendedores e um caixeiro, sendo que, às vezes, nos dias de festas, era necessário contratar mais funcionários, pois o movimento de compra e venda era enorme, coisa que só os funcionários da casa "não davam conta". 
A Casa Bazar Nazaré de Izidoro Cunha Júnior era dividida em espaços destinados ao comércio, família, depósito de mercadorias e capela. Na parte central funcionava o comércio, na parte detrás se localizava o espaço familiar: sala, cozinha, quartos e oratório (capela).

Em nossa pesquisa de campo, fomos recebidos pela dona Vera, conhecida na comunidade por "Verinha", e pelo senhor Reginaldo, filhos do Sr. Izidoro (falecido em 1986) que até hoje residem na casa, apesar de temerem o desmoronamento da ruína. Seus filhos guardam artefatos do passado áureo, do tempo vivido como forma de lembrar o passado com os pais, a família e os amigos da vizinhança. Deles coletamos a maioria das narrativas que analisaremos posteriormente.

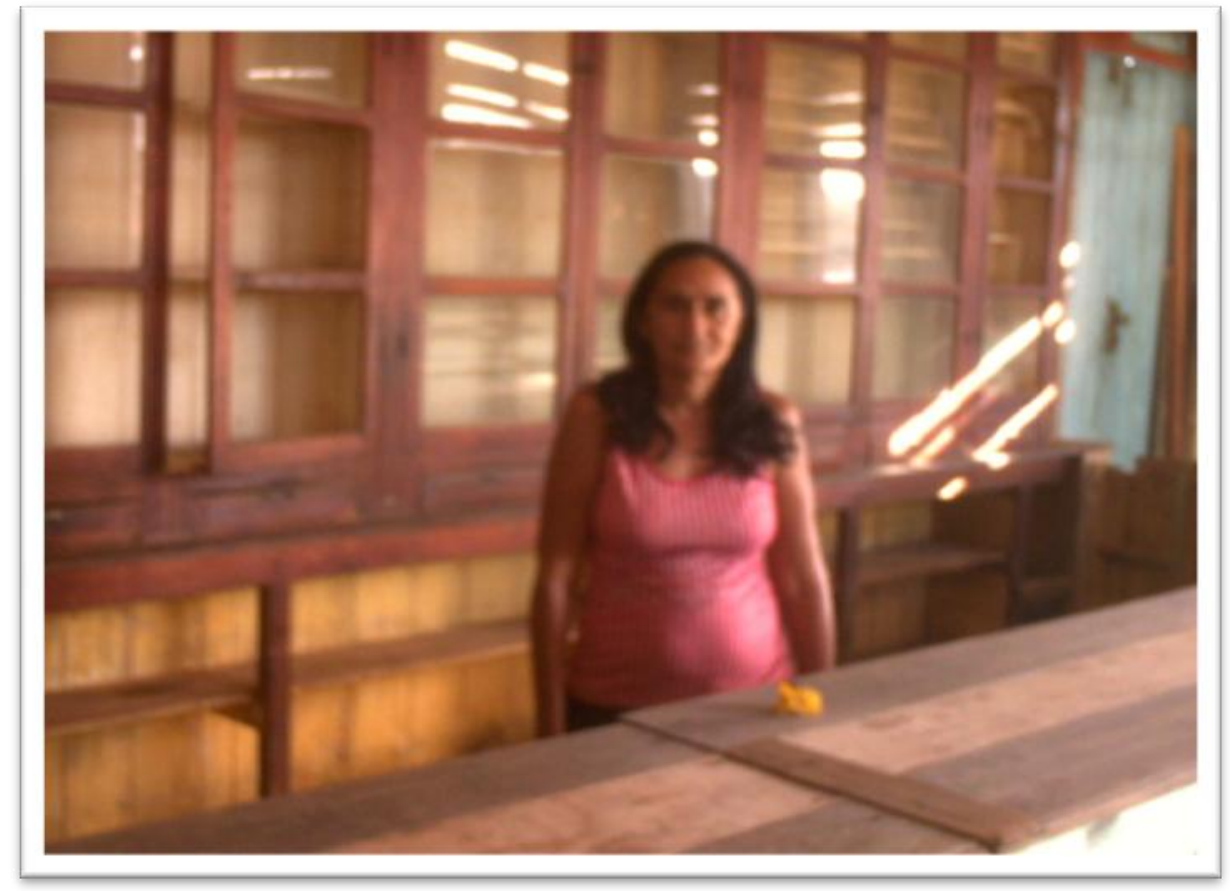

Foto 3 - Senhora Vera Lúcia Cunha.

Ao narrar sobre a memória da Casa e Bazar Nazaré, a senhora Vera Lúcia associa suas memórias às da família Cunha:

Eu guardo comigo as lembranças, que foi muito boa. Sinto muitas lembranças e saudades, né? Porque foi uma vida aqui... Foi uma convivência muito boa aqui, com meus pais, com a minha família, que Deus a tenha num bom lugar. Aqui funcionava o comércio. As mercadorias vinham pra cá de barco, tudo era de barco, porque aqui não tinha estrada. A chegada da estrada foi uma novidade, né? Aqui vendia muito... Tudo tinha muita saída. O meu pai tinha muitos fregueses, que já eram certo pra vir 
comprar. Aqui tinha seis pessoas para atender. Quando era festa, semana santa e arraial, não tinha nem como atender. Era dia e noite. (Vera Lúcia, 55 anos).

Reginaldo Cunha, filho caçula do Sr. Izidoro Cunha Júnior, narrou sobre o tempo vivido com seus pais no comércio fazendo menção ao tempo em que desfrutava das farturas e do lazer proporcionado pela condição social da família, quando os pais estavam presentes (vivos). Na ocasião da entrevista, o narrador emocionou-se e expôs as dificuldades que ele e a irmã vêm passando, relatando o seguinte:

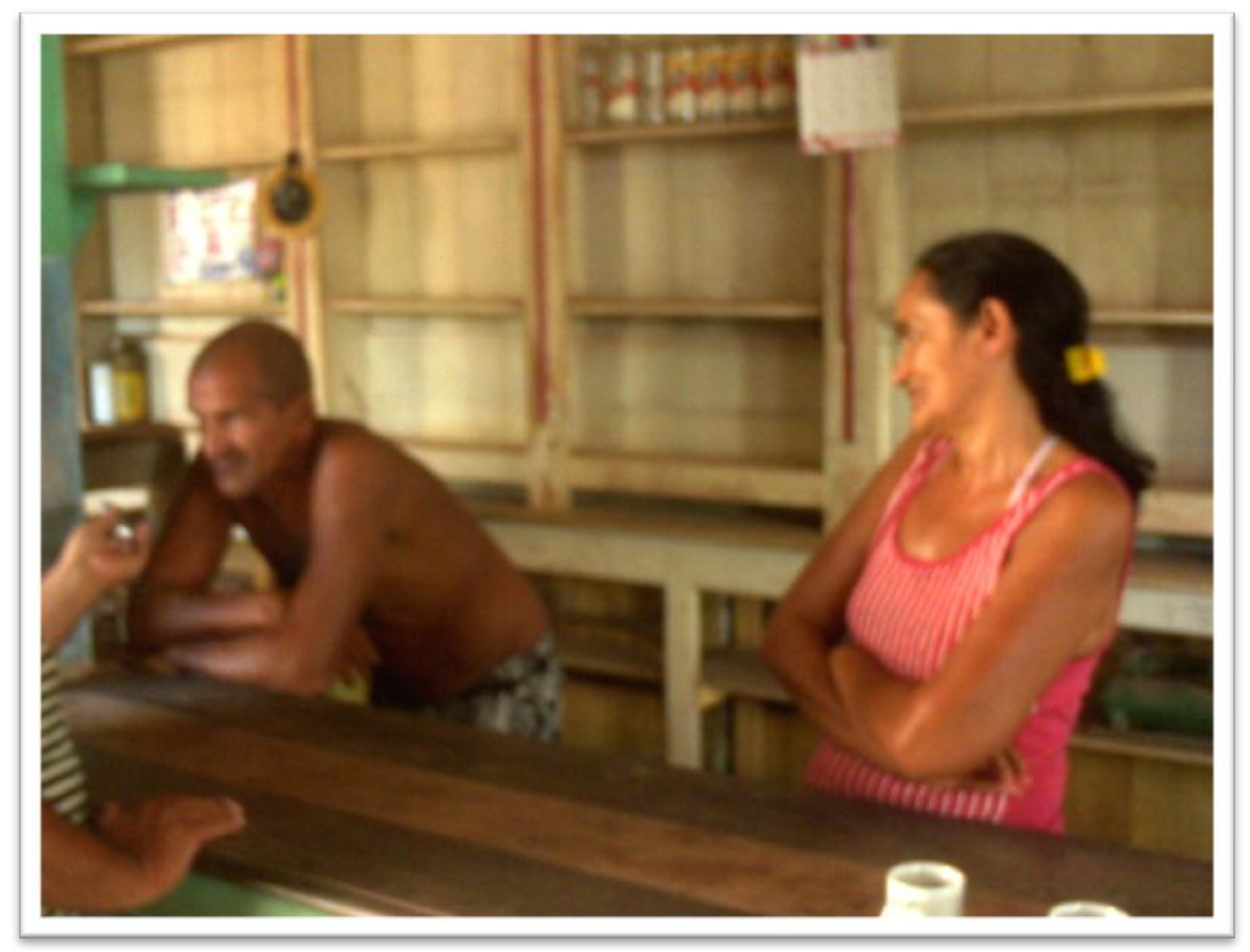

Foto 4 - Reginaldo Cunha e Vera Lúcia Cunha.

Aqui era muito bom! Era muita fartura, isso aqui era tudinho cheio de mercadoria, era tudinho cheio de mercadorias. Hoje do jeito que tá é uma tristeza, é uma tristeza porque tudo acabou-se. Isso aqui e lá no depósito, os barcos era todos cheios de mercadorias, agora do jeito que tá é só muita tristeza... Era muito bom o passadio, muito peixe, muita carne de caça. Era vendido aqui, charque, pirarucu, charque, gurijuba daquelas boas, mesma! Aqui era tudo aberto, cheiro de mercadorias. Aqui tinha toda mercadoria, era fazenda, remédio, óleo, era tudo. O pessoal vinha lá de cima do rio, do Aningal. Aqui vinha gente comprar de muitos lugares. O meu pai tinha muitos amigos, não era muito de conversar com ninguém. Ele tinha muitos amigos. Hoje nós tamos correndo um risco de vida aqui debaixo, a casa tá caindo, mas não podemos fazer nada, porque é herança da família. (Reginaldo Cunha, 60 anos). 


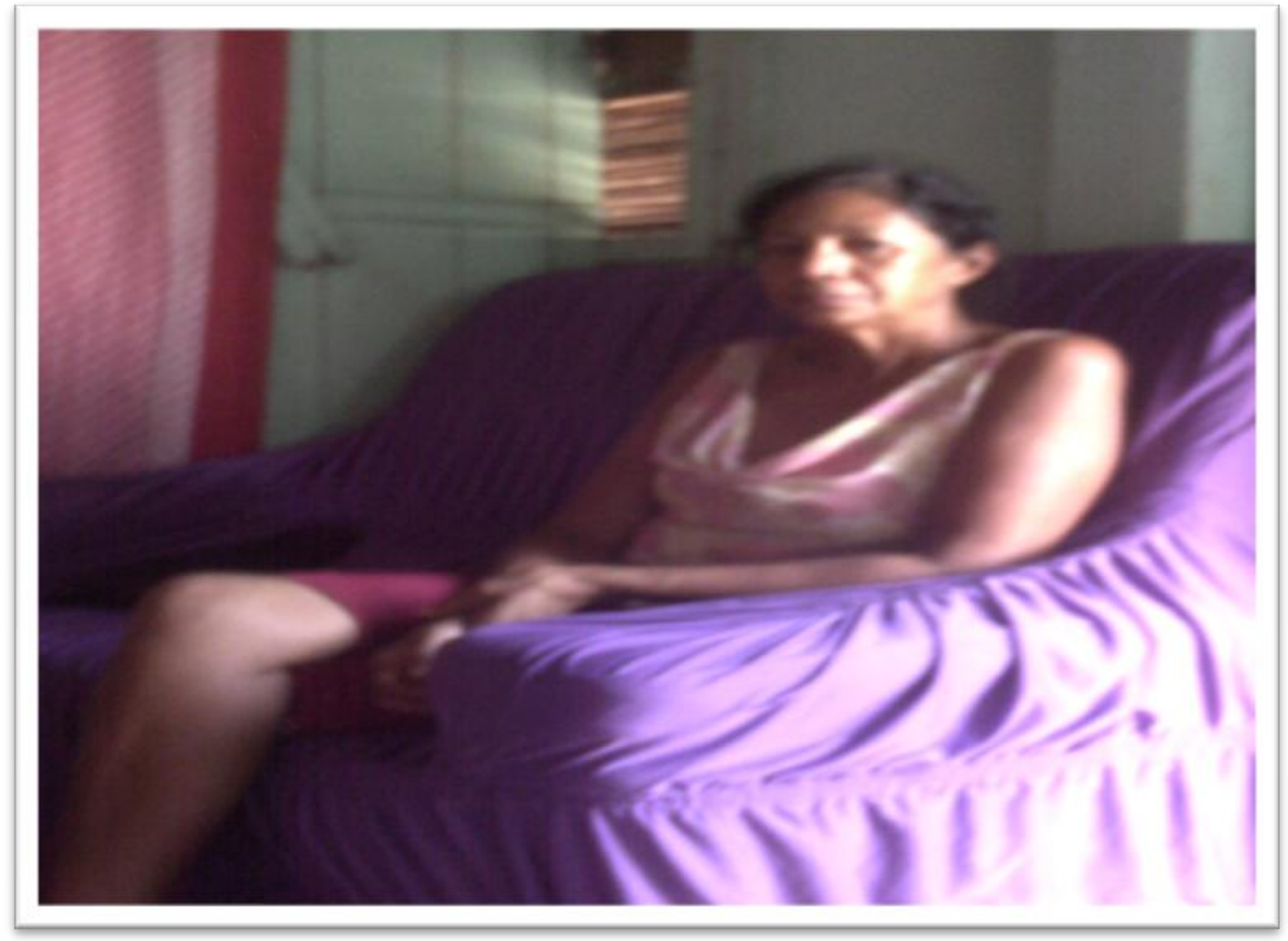

Foto 5 - Dona Ana Pantoja.

Dona Ana Pantoja era filha de um funcionário da Casa Bazar Nazaré, do senhor Izidoro Cunha, lembra do tempo vivido ao lado do pai (já falecido), e nos partilhou das suas lembranças com a seguinte rememoração:

Naquela época eu... se não me foge da memória, pelos anos 60, acho que nos anos 60 por aí assim quando eles vieram para cá. A vida deles era uma vida muito boa. $\mathrm{O}$ velho era uma pessoa muito rica aqui e naquela época o movimento era um movimento total, por sinal era o homem que mais tinha vida financeira boa assim. $\mathrm{O}$ papai gerenciava o comercio dele, ele tinha os meios de transportes, barcos, tinha uma fazendola. Essa casa acho que ela têm uns cem anos, primeiro era do seu Belmiro, depois que ele morreu veio o seu Izidoro e colou o comércio dele aí. Ele vendia todo o tipo de comida: arroz, camarão, arroz, charque, todas essas coisas vendia. Ele era o patrão de quase todas as pessoas daqui Praticamente todo mundo trabalhava aqui, quem não trabalhava aqui, era freguês dele. A minha mãe dizia que ele colaborou para a minha formação e ele colaborou com o meu pai. $\mathrm{O}$ desmoronamento começou quando ele adoeceu, ele tinha diabetes, teve o dedo amputado, depois foi a perna, e aí com abertura da estrada ele foi perdendo a clientela, vieram os crediaristas, e as pessoas começaram também a comprar em Belém. E também acho que ele não tinha uma conta no banco pra depositar, fazer uma poupança. Eu me lembro que a doença dele durou quase três anos, gastando tudo o que ele tinha, foi vendendo as coisas, a fazenda, os gados, o barco e tudo foi se acabando. Os filhos deles foram se casando, casando e ficou só a Vera pra cuidar dele, foi quando ele morreu e depois a mulher dele. Eu tenho uma lembrança muito forte, mas muito forte mesmo dele e da mulher dançando nas quadras juninas. Quando era época de festa junina, parece que tou vendo eles dançando... (Ana Pantoja, 55 anos). 


\title{
O cuidado com os artefatos da ruína Casa Bazar Nazaré e a narrativa fotográfica
}

Não podemos negar hoje que a fotografia é um fato incontestável. Em suas múltiplas formas, ela se afirma como uma outra linguagem, capaz de se expressar e ir além da escrita. Nós a utilizamos para guardar lembranças de acontecimentos íntimos, que não se prende apenas à objetividade científica e nos enquadra num tempo, onde a subjetividade torna-se elemento necessário para compreender as tramas sociais da modernidade.

Ao refletir acerca da contribuição da fotografia para as Ciências Humanas enquanto testemunha do pretérito, Del Priori nos esclarece que

\begin{abstract}
ela serve para testemunhar uma realidade, e em seguida, para lembrar a existência desta mesma realidade. $\mathrm{O}$ tempo tem aqui um papel fundamental, em particular, do ponto de vista histórico e emocional, quando a fotografia é testemunha de mudanças, de transformações físicas e materiais, de desaparecimento de coisas e de entes queridos (Del Priore, 2005: 92).
\end{abstract}

É esse aspecto emocional, sobretudo, decorrente das mudanças ocorridas na geografia da Vila de Santana, bem como da decadência física do proprietário da Casa Bazar Nazaré, que fez com que os moradores da ruína preservassem até hoje os objetos utilizados na casa, ganhando assim uma dimensão simbólica que, por sua vez, transformam-se em linguagens simbólicas, capazes de exercitar a memória de quem mora na ruína e de quem a visita.

É nessa dimensão simbólica que Nasser pensa o símbolo enquanto linguagem que

vai além do nome que identifica um objeto, ampliando seu sentido, dando-lhe novo significado e direção. A linguagem simbólica é usada quando se esgotam as expressões comuns, quando o desconhecido está presente. É a tentativa de suavizar uma saudade e trazer para perto o que está distante, pois o símbolo aproxima significados para realizar uma meta, para expressar algo indizível. (Nasser, 2003: 8).

Durante as pesquisas de campo que fizemos à Santana do Capim, especificamente à Casa e Bazar Nazaré de Izidoro Cunha Júnior, fomos convidados a conhecer alguns objetos da família, até hoje guardados dentro da casa, que se prestam à rememoração do passado e da família, quando os fotografamos com autorização dos herdeiros da casa. Esses objetos transformaram-se em fotografias que, nesta ocasião, são compreendidos como elementos do simbólico produtores de reminiscências. Graças à 
antropologia visual, podemos tecer narrativas que têm o sensível como possibilidade de discussão. E, dessa forma, acompanhamos o questionamento lançado por Sylvia Novaes (2005: 108) para refletir a relação da Antropologia e o uso de imagens, ou seja, a Antropologia Visual: "Como dizer o indizível, como tornar inteligível aquilo que é, antes de mais nada, do domínio do sensível?"

Para dar conta dessa reflexão, a autora pontua sobre a objetividade que a ciência antropológica seguiu junto às demais ciências na busca da objetividade científica, desprezando as paixões, o olhar e a imaginação do sujeito a favor da razão positivista. No entanto, o uso da fotografia enquanto técnica sempre esteve presente nas pesquisas antropológicas para interpretação dos fatos sociais coletados em diversos trabalhos de campo famosos, como é o caso das pesquisas de Malinowsky na obra Os Argonautas do Pacífico Ocidental, e nas pesquisas realizadas por Margaret Mead e Gregory Bateson na década de quarenta.

Ainda citando Novaes para relatar o menosprezo e os pequenos investimentos em pesquisas de caráter visual nas pesquisas antropológicas, mesmo após a contribuição de Mead e Bateson nos resultados importantes para esta ciência, a autora nos adverte que

\footnotetext{
o valor do trabalho documental sobre recursos imagéticos e não-textuais continua sendo pouco explorado e mesmo contestado em vários círculos acadêmicos, a partir da pressuposição de que os textos escritos teriam uma riqueza informativa superior à da imagem. Um antropólogo mestre das imagens como Jean Rouch é certamente mais reconhecido e apreciado por cineastas (vide sua influência notável sobre a Nouvelle vogue e sobre Jean-Luc Godard em especial) do que por seus colegas ou antrópólogos. (Novaes, 2005: 109).
}

Ressalta a autora que, em contraposição à ciência antropológica puramente objetivista, vem-se desabrochando uma nova forma de fazer Antropologia, a qual mergulha na cultura dos sujeitos, da qual um dos grandes expoentes é Clifford Geertz. Essa nova perspectiva na Antropologia valoriza o altruísmo entre pesquisador e pesquisado, em que o "estar lá" do pesquisador o coloca no campo da experiência da cultura do outro, e isto emerge no campo da sensibilidade, participando das experiências, de suas cosmologias.

Finalmente, Novaes (2005) confere à Antropologia Visual a condição de uma das ciências que quebraram as barreiras do cientificismo dos fenômenos sociais, valorizando nestes o campo da sensibilidade e do imaginário social, ou seja, o campo da 
subjetividade dos sujeitos sem desvalorizar a racionalidade da ciência, e fazendo-os interagir através do diálogo plural, em que a imagem é uma narrativa que abarca as redes tecidas pela cultura.

Se um dos objetivos mais caros à Antropologia sempre foi o de contribuir para uma melhor comunicação intercultural, o uso de imagens, muito mais que o de palavras, contribui para essa meta, ao permitir captar e transmitir o que não é imediatamente transmissível no plano linguístico. Certos fenômenos, embora implícitos na lógica da cultura, só podem explicitar no plano das formas sensíveis o seu significado mais profundo. (Novaes, 2005: 110).

O presente estudo compõe-se pelo entrelaçamento das narrativas oral e visual, para refletir sobre as ações sensíveis presentes no tratamento dado pelos moradores do presente aos objetos existentes dentro da casa. Como é possível compreender o sorriso e as lágrimas de dona Vera Lúcia, do senhor Reginaldo e de dona Ana Pantoja quando rememoram, apontando para os artefatos, e falam sobre eles? O sorriso é a memória do pretérito, e as lágrimas seriam o resultado da colisão entre o passado e o presente para eles? O que dizer dos silêncios que aconteceram durante as entrevistas?

Os objetos fotografados abaixo serão descritos numa tentativa de compreendermos os sentimentos atribuidos a eles pela família. Temos consciência de que, por mais densa que seja nossa descrição, não conseguiremos expressar os sentimentos dos nossos narradores, pois estão presentes no campo simbólico, ou seja, estão na subjetividade dos filhos do senhor Izidoro Cunha, cujos sentimentos infelizmente são impossíveis de ser mensurados. 


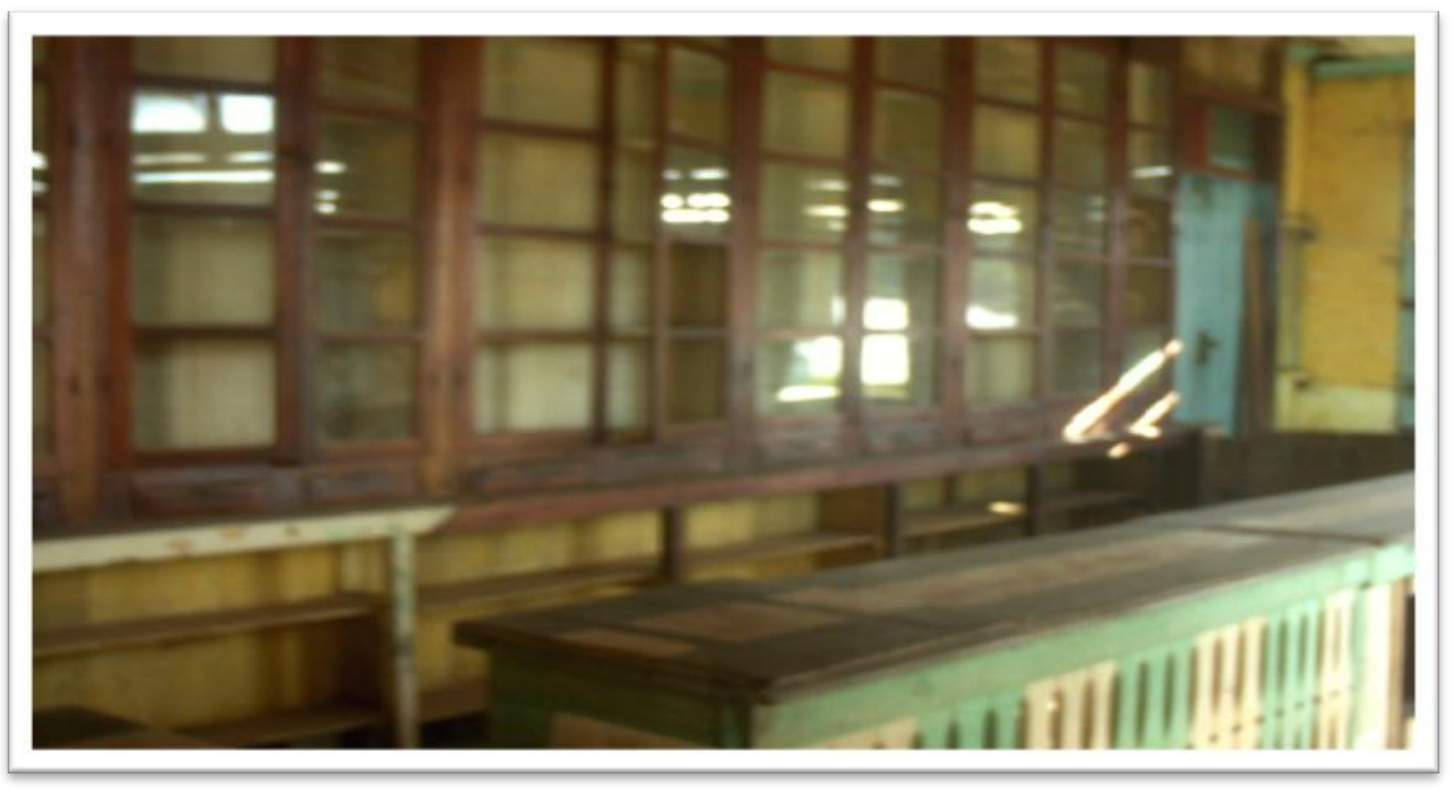

Foto 6 - A prateleira e o balcão.

A prateleira mede aproximadamente quatro metros de altura por oito metros de largura e acompanha quase a totalidade das paredes do compartimento onde funcionava o comércio. Construída de madeira, com divisórias para almoxarifar a diversidade dos produtos a serem vendidos, as portas desse artefato foram retocadas por vidros para permitir a visibilidade dos produtos ao público.

Há ainda, nessa imagem, o balcão, local de relacionamento entre "caixeiros" e "fregueses" do comércio, lócus das transações comerciais. Construído também de madeira, percorre toda a parte frontal da casa e tem aproximadamente um metro e vinte centímetros de diâmetro. É diariamente limpo por dona Vera, e está em bom estado de conservação. 


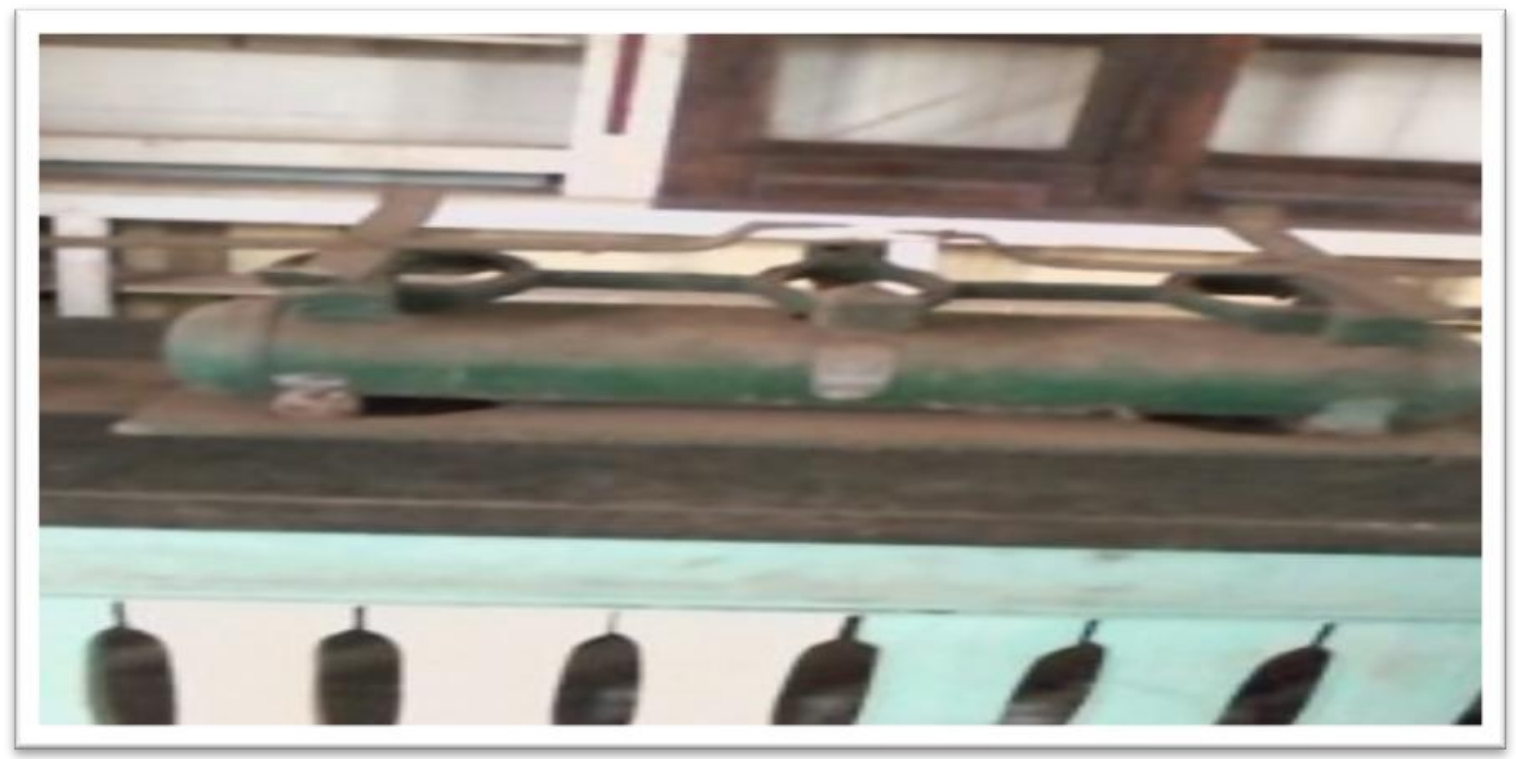

Foto 7 - Balança.

Este artefato de ferro foi aquistado em Belém no início da década de 60, possuía dois "pratos" de cobre. Essas duas peças da balança foram furtadas quando, por esquecimento, deixaram as portas abertas, ficando a outra parte da balança devido ao seu peso, o que inviabilizou seu furto. Segundo o senhor Reginaldo, "ela continua no mesmo local, na mesma posição de quando pesava as coisas" (...). Encontra-se sobre o balcão defronte à porta central da casa em ruínas.

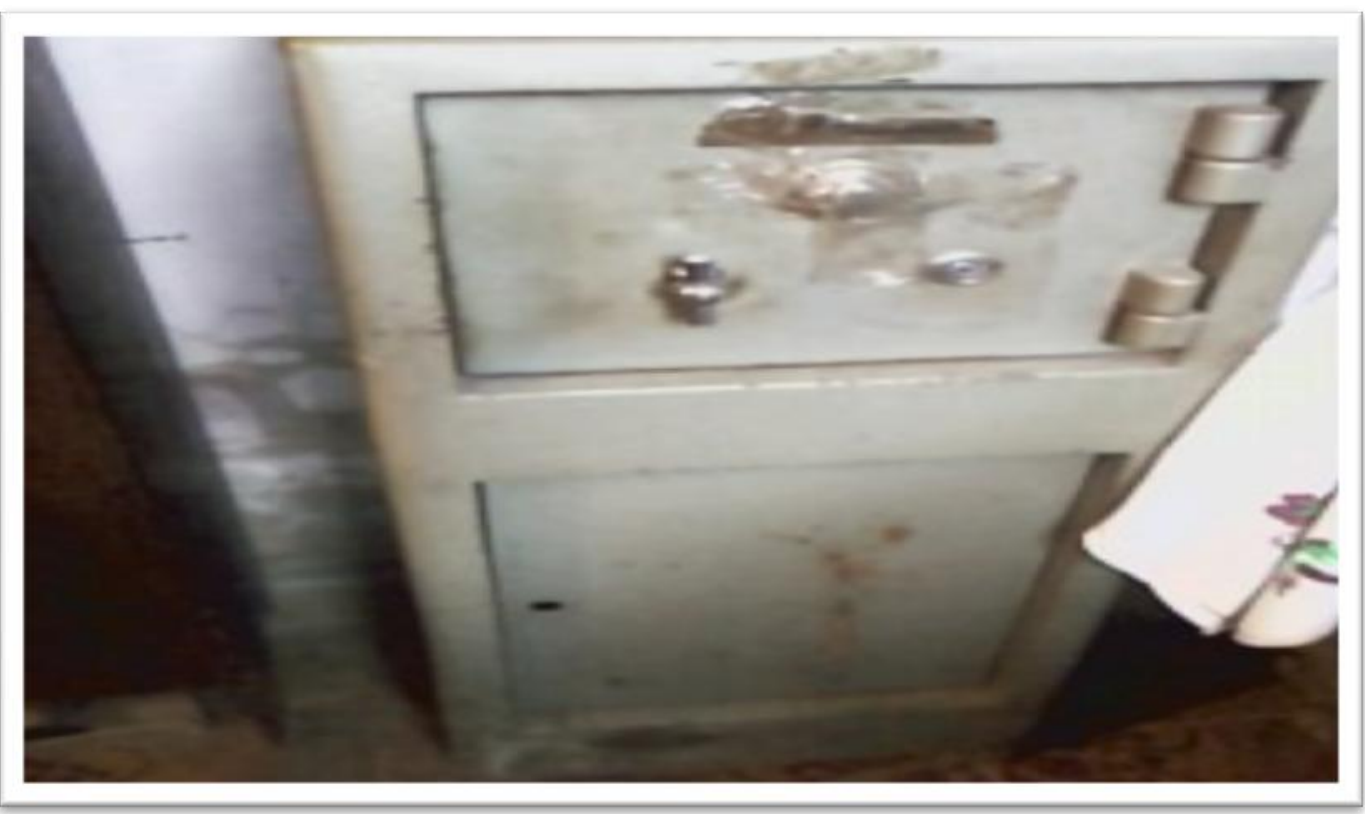

Foto 8 - Cofre. 
Mantido em um dos quartos utilizados pela famíla, o cofre guarda documentos de transações comerciais, cadernos que registram anotações de compras e vendas a crédito do comércio, dinheiros e moedas antigas sem valor monetário para o tempo do Real.

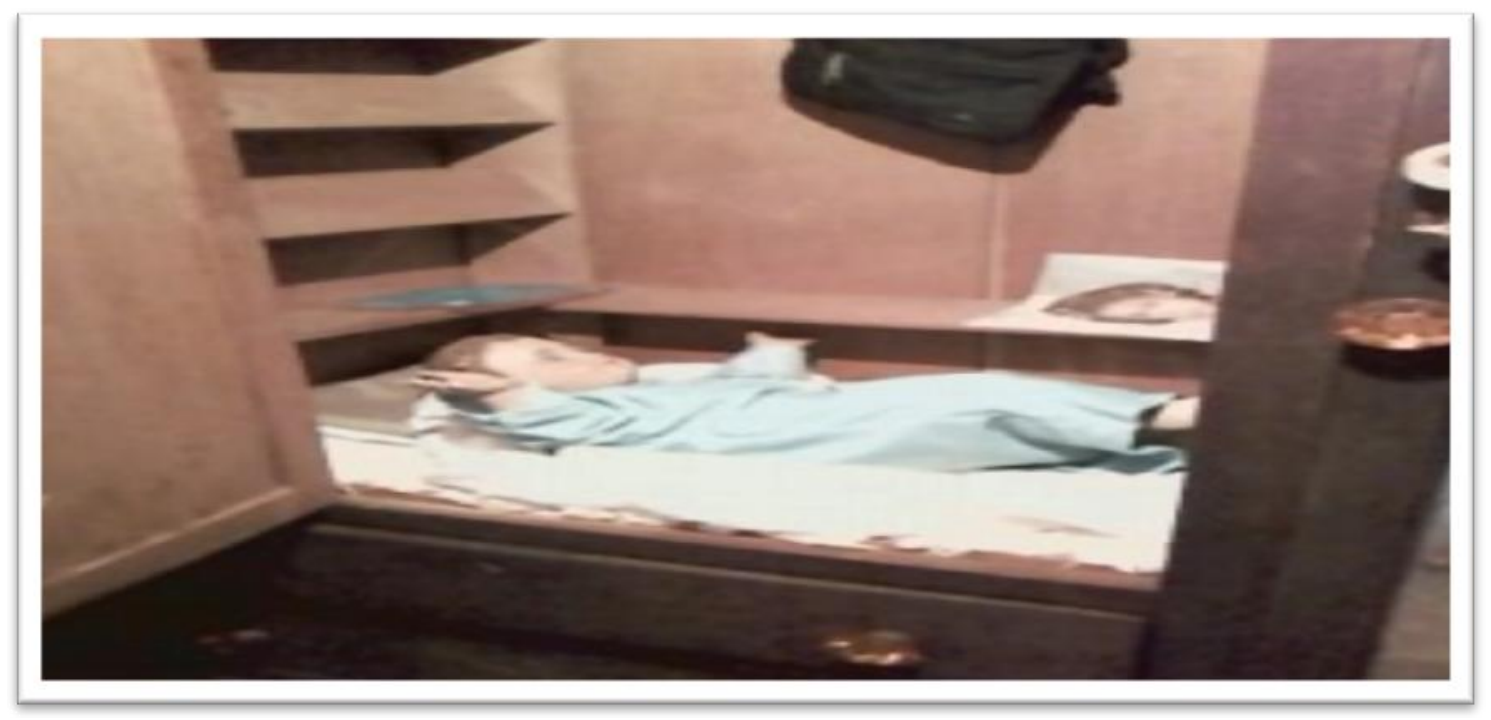

Foto 9 - Menino Jesus.

Ao se abrir a porta do guarda-roupas já meio deteriorado, dona Vera mostrounos a estátua do "Menino Jesus" sob diversos artefatos pequenos. Feita de gesso e envolvida em lençóis brancos, a estátua tem a aparência de uma criança sorrindo. "Isso tudo lembra minha mãe e eu guardo com o maior carinho", relatou a dona da casa com voz chorosa. 


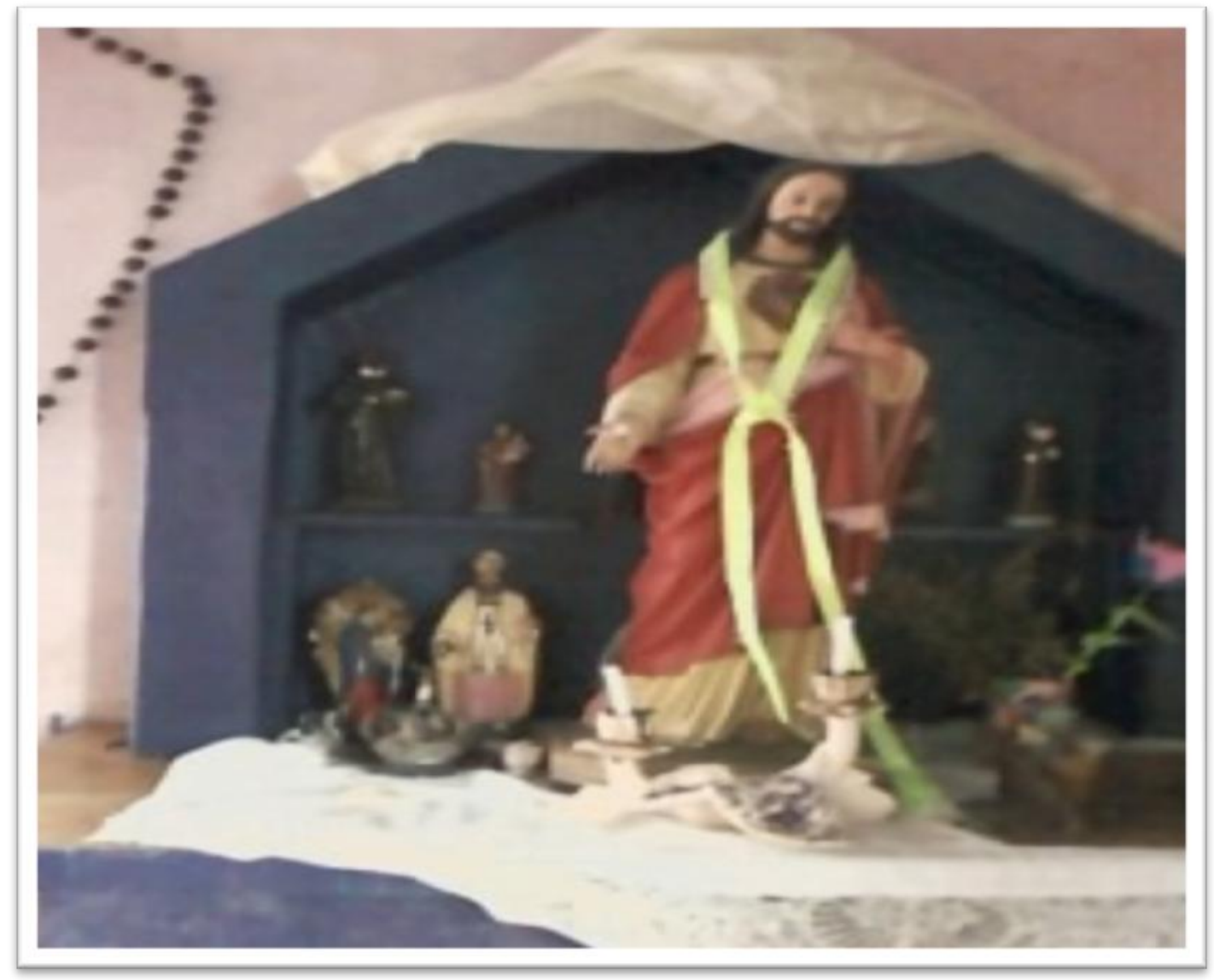

Foto 10 - Oratório.

Localizado numa sala, medindo aproximadamente quatro metros quadrados, com portas que dão acesso à rua lateral da casa, o oratório era o local onde a família e os funcionários da Casa e Bazar Nazaré se reuniam para fazer rezas. Disse dona Vera, na ocasião de nossa visita, que "ao entrarem para trabalhar e quando saíam, todos nós da família e os funcionários vinha pra cá, pra rezar..." "Esse Santo era o Santo de devoção da nossa família. Ele era do meu avô e depois ficou para nosso pai, e eu pretendo passar para um dos meus sobrinhos, porque não tive filhos, me dediquei toda minha vida para a minha família, eu cuidei do papai até Deus levar ele”, acrescentou a narradora.

A narrativa visual etnográfica deste estudo convida-nos a pensar sobre o outro, ou melhor, sobre a cultura do outro através da fotografia, numa relação de alteridade entre quem vive numa ruína e quem está externo a ela. Essa alteridade constitui-se a partir da interação social, mediante o convívio em sociedade e nos fornece a 
construção da nossa capacidade de olhar que, por sua vez, está diretamente relacionada com os atos de simbolização na perspectiva da criação e leitura de imagens. O olhar é aprendido, é treinado de forma articulada com outros olhares. $\mathrm{O}$ olhar não é individual, ele é determinado social e conjunturalmente. É em função do tipo de olhar de uma dada época que são determinados os tipos de imagens e de que forma as pessoas se relacionam com elas. (Achutti, 1997: 42).

O olhar fotográfico sobre a ruína Casa Bazar Nazaré de Izidoro Cunha Júnior, longe de ser um olhar ingênuo, é um olhar voltado para as práticas sociais que o homem faz. A ruína é uma metáfora da modernidade, inclusive da reificação do outro, desfigurado pelo consumismo da sociedade industrial que move as relações sociais no espaço e no tempo, e é nessa esteira que lançamos nossa câmera àquela casa, às pessoas e aos objetos que compõem as narrativas orais e visuais que nelas se inspiram capazes de construir elementos para olhar as mazelas que permeiam a modernidade no século XXI.

\section{À guisa de conclusão}

As narrativas visuais presentes neste estudo evocam a combinação de narrativas orais, colhidas das memórias dos descendentes e vizinhos do Senhor Izidoro Cunha Júnior, e fotografias. Esses elementos são imprescindíveis para compreender como os elementos tempo e espaço podem se cristalizar como um fragmento do passado, não um passado estanque, mas um tempo pretérito que está em movimento, mesmo nostálgico. E essa nostalgia é importante, para a preservação dos objetos do passado e neles a história da família, a transformação do espaço vivido, da vila de Santana do Capim, principalmente nos dias atuais, quando as empresas de mineração avançam em direção ao rio ameaçando a ecologia da região e gestando transformações que comprometem a vida da população da vila.

O estudo também nos convida a pensar acerca da necessidade de projetos de pesquisas sobre a memória e de narrativas orais da população de Santana do Capim, em que a Antropologia Visual tem muito a contribuir para o registro da resistência da referida população, de modo a não se esquecer do seu passado quando o presente ameaça a vida em comunidade. Os resultados desta pesquisa e de outras que a sucederão poderão subsidiar investimentos em políticas públicas que valorizem o patrimônio cultural da Vila Santana do Capim e região ribeirinha do município de Aurora do Pará. 


\section{Referências}

ACHUTTI, Luiz Eduardo R. Fotoetnografia. Um estudo de Antropologia Visual sobre o cotidiano, lixo e trabalho. Porto Alegre: Tomo Editorial, Palmarinca, 1997.

AUMONT, Jacques. Do visual ao imaginário. In: A Imagem. Campinas: Papirus, 2006. BENJAMIN, Walter. O narrador: considerações sobre a obra de Nikolai Leskov. In: Magia e técnica, arte e política. Tradução de Sérgio Paulo Rouanet. 7 ed., São Paulo: Brasiliense, 1994.

BOSI, Ecléa. Memória e Sociedade. Lembrança de Velhos. 14 ed., São Paulo: Companhia das Letras, 1994.

COLLEYN, Jean-Paul. Entrevista: Jean Rouch, 54 anos sem tripé. In: Cadernos de Antropologia e Imagem I. Antropologia e Cinema - Primeiros Encontros. Rio de Janeiro: UERJ, 1995.

COOLLIER Jr, John. Antropologia Visual: a fotografia como método de pesquisa. USP, EPV, 1973.

DEL PRIORE, Mary. A fotografia como objeto da memória. In: Cultura Popular e Educação. Salto para o Futuro/TV Escola/SEED/MEC. Brasília, 2008.

DUBOIS, Philippe. O ato fotográfico. In: O ato fotográfico e outros ensaios. Campinas: Papirus, 1993.

DURKHEIM, Émile. Sociologia e Filosofia. Rio de Janeiro: Forense Universitária, 1970.

DURAND, Gilbert. Situação atual do símbolo e da imagem. In: A fé do sapateiro. Brasília: Editora da UnB, 1995.

EDWARDS, Elizabeth. Antropologia e fotografia. In: Cadernos de Antropologia e Imagem I. Antropologia e Cinema - Primeiros Encontros. Rio de Janeiro: UERJ.

FLUSSER, Vilém. Filosofia da caixa preta. Ensaios para uma futura filosofia da fotografia. Rio de Janeiro: Relume Dumará, 2002.

FRANCE, Claudine de. Cinema e Antropologia. Campinas: UNICAMP, 1998.

GURHAN, Mílton. Fotografia e pesquisa antropológica. Museu do Índio. Mimeo.

HORIZONTES ANTROPOLÓGICOS. Entrevista com Mílton Gurhan. Ano 1, n. 2, Porto Alegre, 1995.

LE GOFF, Jacques. História e memória. Tradução de Bernardo Leitão. Campinas: Editora da UNICAMP, 1990.

MACDOUGALL, David. "Mas afinal, existe realmente uma antropologia visual?". In: Catálogo II, Mostra Internacional do Filme Etnográfico. Interior Produções, 20 set/02, MAFFESOLI, Michel. O imaginário é uma realidade. Revista FAMECOS, n. 15, Porto Alegre, 2001.

MANGUE, Alberto. O espectador comum: a imagem como narrativa. In: Lendo Imagens. São Paulo: Companhia das Letras, 2001.

MARIN, Rosa A.; CASTRO, Edna. No Caminho de pedras de Abacatal: experiência social de grupos negros no Pará. Belém: NAEA/UFPA, 2004.

NASSER, Maria Celina. O que dizem os Símbolos? São Paulo: Paulus, 2003.

NOVAES, Sylvia Catuby. $O$ uso da imagem na Antropologia. In: SAMAIN, Etienne (org.). O fotográfico. São Paulo: HUCITEC/SENAC, 2005. out. 1994.

POLLAK, Michel. Memória, esquecimento, silêncio. Estudos históricos. v. 2, n. 3, Rio de Janeiro, 1989.

PIAULT, Marc Henri. Real e ficção. In: KHOURI, Mauro P. (org.). Imagem e memória. Ensaios em Antropologia Visual. Rio de Janeiro: Garamond, 2001. 
ROCHA, Ana Luiza Carvalho da. "Antropologia das formas sensiveis: entre o visível e $o$ invisivel, afloração de símbolos" In: Horizontes Antropológicos. Antropologia Visual, Ano I, v. 2, 1995.

SAMAIN, Etienne. Balinese Character (Re) visitado. Uma introdução à obra visual de Gregory Bateson e Margaret Mead. In: ALVES, André. Os argonautas do mangue. Campinas: UNICAMP/Imprensa Oficial do Estado de São Paulo, 2004.

SEVERI, Carlo. A palavra emprestada ou como falam as imagens. Revista de Antropologia, v. 52, n. 2, São Paulo, USP, 2009.

SIMMEL. Georg. A Filosofia da Paisagem. Tradução de Arthur Mourão. Covilhã: LusoSofia-press, 2009.

TODOROV, Tzvetan. As estruturas narrativas. Tradução de Leyla Perrone Moisés. São Paulo: Perspectiva, 2006.

Recebido em: 22/03/2015

Aprovado em: 10/06/2015 